\title{
Factors associated with diarrhoea and acute respiratory infection in children under- 5 years old in Ghana: an analysis of a national cross-sectional survey
}

Paschal Awingura Apanga ${ }^{1 *}$ and Maxwell Tii Kumbeni ${ }^{2}$

\begin{abstract}
Background: Diarrhoea and acute respiratory infection (ARI) are major causes of morbidity and mortality in children under-5 years old in Ghana. The aim of the study was to assess factors associated with diarrhoea and ARI in children under-5 years old.

Methods: We analysed nationally representative data from the 2017-2018 Ghana Multiple Indicator Cluster Survey (MICS) on 8879 children under-5 years old. Multivariable logistic regression was used to assess the factors associated with diarrhoea and ARI. We applied sample weights, stratification and clustering to account for the sampling design of the MICS.

Results: The prevalence of diarrhoea was 17.0\% (95\% Cl: 15.70, 18.24\%). Children aged 6-11 months [Adjusted prevalence odds ratio (aPOR): 2.06, 95\% Cl: 1.45, 2.92], and 12-23 months (aPOR: 2.37, 95\% Cl: 1.67, 3.35), had higher prevalence of diarrhoea compared to children aged 0-5 months. Children whose mothers had a college or higher education (aPOR: $0.41,95 \% \mathrm{Cl}: 0.22,0.78$ ), and a secondary education (aPOR: $0.66,95 \% \mathrm{Cl}: 0.51,0.86$ ), had 59\% and $34 \%$ lower odds of diarrhoea respectively, compared to children whose mothers had no formal education. Children from the richest households (aPOR: $0.58,95 \%$ Cl: $0.39,0.86$ ), had $42 \%$ lower odds of diarrhoea compared to children from the poorest households. Children resident in rural areas had 22\% lower odds of diarrhoea compared to their peers in urban areas (aPOR: $0.78,95 \% \mathrm{Cl}$ : 0.63, 0.98). The prevalence of ARI was 33.3\% (95\% Cl: 31.72, 34.82\%). Children aged 6-11 months (aPOR: 1.43, 95\% Cl: 1.06, 1.93), and 12-23 months (aPOR: 1.41, 95\% Cl: 1.10, 1.82), had higher prevalence of ARI compared to children aged 0-5 months.

Conclusions: This study suggests that the prevalence of diarrhoea and ARI among children aged 6-11 and 12-23 months was higher compared to children aged 0-5 months. Children under-5 years old whose mothers had a secondary or higher education had a lower prevalence of diarrhoea compared to children whose mothers had no formal education.
\end{abstract}

Keywords: Diarrhoea, Acute respiratory infection, Children under-5 years, Ghana

\footnotetext{
* Correspondence: awingura@yahoo.com

'University of Nevada, Reno, School of Community of Health Sciences, Reno, USA

Full list of author information is available at the end of the article
}

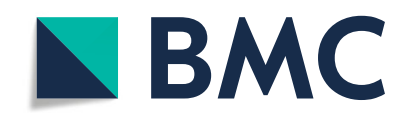

(- The Author(s). 2021 Open Access This article is licensed under a Creative Commons Attribution 4.0 International License, which permits use, sharing, adaptation, distribution and reproduction in any medium or format, as long as you give appropriate credit to the original author(s) and the source, provide a link to the Creative Commons licence, and indicate if changes were made. The images or other third party material in this article are included in the article's Creative Commons licence, unless indicated otherwise in a credit line to the material. If material is not included in the article's Creative Commons licence and your intended use is not permitted by statutory regulation or exceeds the permitted use, you will need to obtain permission directly from the copyright holder. To view a copy of this licence, visit http://creativecommons.org/licenses/by/4.0/. The Creative Commons Public Domain Dedication waiver (http://creativecommons.org/publicdomain/zero/1.0/) applies to the data made available in this article, unless otherwise stated in a credit line to the data. 


\section{Introduction}

Globally, diarrhoea and acute respiratory infections (ARIs) are major causes of mortality among children under-5 years old [1, 2]. Children in Sub-Saharan Africa are more than 15 times at risk of death before age 5 as compared to children in high income countries, with some of these deaths attributable to diarrhoeal disease and ARI [3]. Due to the survival threat posed by these health events, the Sustainable Development Goal 3 aims to reduce under -5 mortality to as low as 25 per 1000 live births by 2030 [4]. The World Health Organization (WHO) has also recommended for countries to provide all children with essential health services without undue financial hardship as part of measures to reduce under-5 morbidity and mortality [3].

In Ghana, diarrhoea and ARI are leading causes of under-5 mortality [5]. Diarrhoea and ARI are part of the top 10 causes of hospital admissions and mortality in children under-5 years old in Ghana [6]. Ghana's under5 mortality has declined from 82 per 1000 live births in 2011 to 56 per 1000 live births in 2018 [7, 8]. Whilst there seem to be a considerable decline in under-5 mortality, Kipp et al. observed that Ghana is among eight countries in Africa making little progress towards the reduction in under-5 mortality [9]. The high diarrhoea and ARI morbidities in children under- 5 years of age are largely blamed for the slow pace in decline in under- 5 mortality $[10,11]$. Several policies and interventions have been implemented in Ghana including, the Free maternal health policy, Child health policy 2007-2015, Newborn care strategy 2014-2018, and Community-based health planning and services (CHPS) policy as part of measures to address the high under-5 morbidity and mortality in the country [12-15]. Therefore, assessing factors associated with diarrhoea and ARI would be relevant to Ghana where these health events are strongly associated with under-5 mortality $[5,6]$.

There are limited studies in Ghana on the prevalence and factors associated with diarrhoea and ARI in children under-5 years old [11, 16]. Many of these studies were not representative of children under- 5 years in Ghana as they were restricted to selected districts and hospitals in the country [17-19]. Therefore we used data from the 2017-2018 Ghana Multiple Indicator Cluster Survey (MICS) [20], a national representative household survey, to assess factors associated with diarrhoea and ARI in children under- 5 years old.

\section{Methods}

\section{Study population}

Our study population was children under-5 years old (0-59 months) in Ghana. We analysed data from the 2017-2018 MICS conducted in Ghana. The MICS is a national representative household survey conducted in many countries in the world with assistance from United Nations Children's Fund (UNICEF), and provides robust data on women and children [21]. The MICS is a cross-sectional design, which employs a two-stage sampling technique which selects census enumeration areas from each sampling strata proportional to the number of households in an enumeration area. The second stage involves selection of households from each enumeration area to form survey clusters using systematic random sampling. Eligible mothers with children under-5 years old in selected households were interviewed $[20,22]$. The response rate for eligible mothers with children under-5 years old was $99.7 \%$. Details of MICS sampling procedures have been published [21].

\section{Primary outcomes}

Our primary outcomes of interest were diarrhoea and acute respiratory infection (ARI). A child had diarrhoea if the mother or primary caretaker reported that the child had three or more loose or watery stools per day, or blood in stool two weeks prior to the survey. A child had ARI if the mother reported the child was ill with cough or difficulty in breathing [23], in the last two weeks. The term "mother" in our study refers to a biological mother or a female primary caretaker of the child under-5 years living in the same household.

\section{Primary variables of interest}

We assessed whether child, maternal and household level factors were associated with diarrhoea and ARI in children under- 5 years of age. These factors included: child's age (0-5, 6-11, 12-23, 24-59 months); gender (boy, girl); child's health insurance (yes, no); mother's education (no formal education, primary, secondary, college or higher education); source of drinking water (improved, unimproved); sanitation (improved, unimproved); floor material (improved, unimproved); household wealth (poorest, poor, middle, rich, richest); place of residence (rural, urban); and presence of hand washing station in dwelling (yes, no).

We used the WHO/ UNICEF Joint Monitoring Programme for Water Supply, Sanitation and Hygiene (JMP) to categorize our source of drinking water [24]. An improved water source included source of drinking water from boreholes, piped water or tube wells, protected dug wells, protected springs, tanker-truck, rain water and packaged water, whilst an unimproved water source included unprotected springs, unprotected dug wells, and surface water collected directly from river, dam, lake, pond, stream, canal and irrigation channels. A household sanitation was considered unimproved if members of the household used pit latrines without a slab or platform, hanging latrines or bucket latrines, whilst improved sanitation included flush/pour flush 
toilet, pit latrine with slab, ventilated improved latrine and composting toilet according to JMP [25]. A household floor was considered improved if it was made up of cement, ceramic tiles, vinyl asphalt strips, parquet, polished wood, whilst floor materials such as earth, sand, dung, wood planks, palm, bamboo were considered unimproved [26]. Household wealth was categorized into wealth quintiles (poorest, poor, middle, rich, richest), and was determined using principal component analysis [27]. Our variable selection was guided based on previous studies [11, 16, 28], and data available in MICS.

\section{Data analysis}

Data were analysed using descriptive statistics and complex survey multivariable logistic regression. Descriptive statistics were used to describe our study sample, and to assess the prevalence of our primary outcomes (diarrhoea and ARI) in our study sample.

Complex survey regression models (i.e. model for diarrhoea and a separate model for ARI) were used to assess the relationship between our primary variables of interest and primary outcomes. We conducted both univariate and multivariable logistic regression analyses for each of the primary outcomes. Univariate analysis was conducted for all primary variables in relation to their respective outcomes. Univariate analysis with a $P$-value of less than 0.2 was used to select variables into the multivariable regression models. Variables that had a $P$-value of greater than 0.2 at univariate analysis but were clinically relevant or might have some biological plausibility with the outcome were included in their respective multivariable regression model. We also tested for multicollinearity for each of the multivariable regression models using pairwise correlation matrix, variance inflation factor and tolerance, and eigensystem analysis of correlation matrix [29], to ensure that there was no multicollinearity issues. We assessed the fitness of each of our models using the global null hypothesis test. A $P$-value of less than 0.05 was considered statistically significant. Missing data was not a problem in our study as only the sanitation variable had missingness of $0.01 \%$ (i.e. only one child), which was dropped.

In all our descriptive statistics and regression analyses, we applied sample weights, stratification and clustering to account for the complex survey design, and to ensure the representativeness of the data. Data were analysed using SAS version 9.3 (SAS Institute, Cary, NC).

\section{Results}

\section{Study sample}

The study population and analytic sample was made up of 8879 children under- 5 years old. The mean age of a child was $30 \pm 7.3$ months. One in 2 children were females $(50.8 \%)$, and more than half of the number of children in our study had a health insurance (58.4\%). Many of the children were living in the rural setting (56.9\%) (Table 1). The overall prevalence of diarrhoea in our study was $17.0 \%$ (95\% CI: $15.70,18.24 \%$ ), and the

Table 1 Characteristics of the study population $(n=8879)$

\begin{tabular}{|c|c|}
\hline Variable & $\mathrm{N}(\%)$ or Mean (SD) \\
\hline Child age (months) & $30(7.3)$ \\
\hline \multicolumn{2}{|l|}{ Child age (months) } \\
\hline $0-5$ & $830(9.4)$ \\
\hline $6-11$ & $871(9.8)$ \\
\hline $12-23$ & $1694(19.1)$ \\
\hline $24-59$ & $5483(61.8)$ \\
\hline \multicolumn{2}{|l|}{ Gender } \\
\hline Boy & $4370(49.2)$ \\
\hline Girl & 4509 (50.8) \\
\hline \multicolumn{2}{|l|}{ Child's health insurance status } \\
\hline Yes & $5187(58.4)$ \\
\hline No & 3692 (41.6) \\
\hline \multicolumn{2}{|l|}{ Mothers education } \\
\hline No formal education & $2431(27.4)$ \\
\hline Primary & $1792(20.2)$ \\
\hline Secondary & $4213(47.5)$ \\
\hline College or higher education & $443(5.0)$ \\
\hline \multicolumn{2}{|l|}{ Source of drinking water } \\
\hline Unimproved & $1386(15.6)$ \\
\hline Improved & $7493(84.4)$ \\
\hline \multicolumn{2}{|l|}{ Sanitation } \\
\hline Unimproved & $3323(37.4)$ \\
\hline Improved & $5556(62.6)$ \\
\hline \multicolumn{2}{|l|}{ Floor material } \\
\hline Improved & $8083(91)$ \\
\hline Unimproved & $796(9.0)$ \\
\hline \multicolumn{2}{|l|}{ Household Wealth } \\
\hline Poorest & $1966(22.1)$ \\
\hline Poor & $1834(20.7)$ \\
\hline Middle & $1771(19.9)$ \\
\hline Rich & $1678(18.9)$ \\
\hline Richest & $1630(18.4)$ \\
\hline \multicolumn{2}{|l|}{ Place of residence } \\
\hline Urban & $3825(43.1)$ \\
\hline Rural & $5054(56.9)$ \\
\hline \multicolumn{2}{|c|}{ Presence of handwashing station in dwelling } \\
\hline No & $8248(92.9)$ \\
\hline Yes & $631(7.1)$ \\
\hline
\end{tabular}


overall prevalence of ARI was 33.3\% (95\% CI: 31.72, 34.82\%) [Results not shown].

\section{Factors associated with diarrhoea and ARI}

The multivariable regression analysis on diarrhoea showed that children aged 12-23 months and 6-11 months had 2.37 and 2.06 respectively, times the odds of diarrhoea compared to children aged 0-5 months. Children whose mothers had a secondary education, and a college or higher education had $34 \%$ and $59 \%$ lower odds of diarrhoea respectively, compared to children whose mothers had no formal education. Children from the richest households had $42 \%$ lower odds of diarrhoea compared to children from the poorest households [Adjusted prevalence odds ratio (aPOR): 0.58, 95\% CI: 0.39, $0.86]$. Children resident in rural settings had $22 \%$ lower odds of diarrhoea compared to those in urban settings (aPOR: 0.78, 95\% CI: 0.63, 0.98) (Table 2).

Our multivariable regression analysis on ARI revealed that children aged 6-11 months (aPOR: 1.43, 95\% CI: $1.06,1.93$ ), and $12-23$ months (aPOR: $1.41,95 \% \mathrm{CI}$ : $1.10,1.82)$, had higher prevalence of ARI compared to children aged 0-5 months. All other variables were not associated with ARI (Table 3).

\section{Discussion}

Our study found that the prevalence of diarrhoea and ARI were $17.0 \%$ and $33.3 \%$ respectively. We also observed that children aged 6-11 and 12-23 months were associated with higher odds of diarrhoea and ARI. Children whose mothers had at least a secondary education, and children from the richest households were associated with lower odds of diarrhoea. Children resident in rural settings were associated with lower odds of diarrhoea.

The prevalence of diarrhoea in our study was lower than that reported by Amugsi et al. in their analysis of the 2008 Ghana Demographic and Health Survey (i.e. 20.9\%) [11]. The prevalence of diarrhoea reported in our study indicates a slow decline in diarrhoea prevalence over the past 10 years in children under- 5 years old, and may be part of the reasons why Ghana is making little progress towards the reduction of under-5 mortality [9]. Ghana may need to implement programmes focussed on diarrhoea reduction if a rapid decline is to be achieved.

With regards to ARI, the prevalence of ARI in our study was higher than that reported by Amugsi et al. in Ghana (22.4\%), but lower than that reported in Nigeria (64.9\%), Cameroon (54.7\%), and India (41.6\%) [11, 30-32]. The differences in prevalence of ARI might be attributed to variations in case definitions for ARI, child age, study population, study period and seasonality.

Our study also found that children aged 6-11 months and 12-23 months had higher odds of diarrhoea and
ARI compared to their peers aged $0-5$ months. This finding is consistent with many previous studies [11, 33-36]. Children within the ages of $0-5$ months in Ghana are usually exclusively breastfed [8], and therefore our observed finding may be a reflection of the important role exclusive breast feeding plays in reducing diarrhoea and respiratory infection in children who are exclusively breastfed [37, 38]. The lower prevalence of diarrhoea among children aged $0-5$ months may also be attributed to the innate immunity and less exposure to contaminated agents compared to children aged 6-23 months as children within this age group usually receive supplementary /complementary foods [38].

Our results also showed that children whose mothers had at least a secondary education had lower odds of diarrhoea compared to children whose mothers had no formal education. This is not surprising as education helps women to be well informed on how to access and apply information on child health. This finding in our study has been reported by other studies $[16,33]$. We also found that children in the richest households had lower odds of diarrhoea compared to children in the poorest households. This finding is in conformity with previous studies in Ghana and Ethiopia [16, 39], but inconsistent with findings from Tanzania [40]. In our study, we also found that children resident in rural settings reported lower odds of diarrhoea compared to children in urban settings. This is consistent with the findings of Kumi-Kyereme and his colleague in Ghana. Our finding was also inconsistent with a recent systematic review in Ethiopia [41]. The finding in our study may be due to the urban health penalty, which posits that urban areas tend to concentrate poor people and expose residents to unhealthy environments, leading to a disproportionate burden of poor health [42]. This could possibly account for the higher prevalence of diarrhoea in children resident in urban areas compared to rural areas.

We also did not find an association between the presence of a handwashing station in the home and diarrhoea or ARI. The presence of a handwashing station may not necessarily reflect handwashing behaviour and may be the reason for our observed finding. Our findings were consistent with the findings of Kamm et al. in western Kenya [43]. There is mixed evidence on the role of a designated place for handwashing on diarrhoea or ARI prevalence in children. Whilst a randomized controlled trial in Bangladesh found no association between a handwashing station and an influenza-like illness or influenza [44], an observational study found that handwashing stations were associated with lower prevalence of respiratory infection in children [45]. A cluster-randomised controlled trial in Kenya reported that handwashing stations did not reduce childhood diarrhoea [46]. However, a systematic 
Table 2 Factors associated with diarrhea in children under-5 years old ( $n=8879$ )

\begin{tabular}{|c|c|c|}
\hline Variable & Unadjusted OR (95\% Cl) & Adjusted OR $(95 \% \mathrm{Cl})$ \\
\hline \multicolumn{3}{|l|}{ Child age (months) } \\
\hline $0-5$ & 1 & 1 \\
\hline $6-11$ & $2.01(1.44,2.82)$ & $2.06(1.45,2.92) *$ \\
\hline $12-23$ & $2.31(1.63,3.28)$ & $2.37(1.67,3.35) *$ \\
\hline $24-59$ & $1.20(0.85,1.69)$ & $1.15(0.82,1.63)$ \\
\hline \multicolumn{3}{|l|}{ Gender ** } \\
\hline Boy & 1 & 1 \\
\hline Girl & $0.95(0.80,1.13)$ & $0.95(0.80,1.13)$ \\
\hline \multicolumn{3}{|l|}{ Child's health insurance status } \\
\hline Yes & 1 & 1 \\
\hline No & $1.14(0.96,1.35)$ & $1.02(0.86,1.20)$ \\
\hline \multicolumn{3}{|l|}{ Mothers education } \\
\hline No formal education & 1 & 1 \\
\hline Primary & $0.89(0.70,1.13)$ & $0.91(0.71,1.17)$ \\
\hline Secondary & $0.59(0.47,0.75)$ & $0.66(0.51,0.86) *$ \\
\hline College or higher education & $0.27(0.16,0.46)$ & $0.41(0.22,0.78) *$ \\
\hline \multicolumn{3}{|l|}{ Source of drinking water } \\
\hline Unimproved & 1 & 1 \\
\hline Improved & $0.64(0.48,0.85)$ & $0.78(0.54,1.11)$ \\
\hline \multicolumn{3}{|l|}{ Sanitation } \\
\hline Unimproved & 1 & 1 \\
\hline Improved & $0.68(0.58,0.81)$ & $0.86(0.71,1.05)$ \\
\hline \multicolumn{3}{|l|}{ Floor material ** } \\
\hline Improved & 1 & 1 \\
\hline Unimproved & $1.14(0.92,1.42)$ & $0.84(0.64,1.11)$ \\
\hline \multicolumn{3}{|l|}{ Household Wealth } \\
\hline Poorest & 1 & 1 \\
\hline Poor & $0.84(0.69,1.02)$ & $0.92(0.74,1.14)$ \\
\hline Middle & $0.81(0.61,1.09)$ & $0.94(0.64,1.37)$ \\
\hline Rich & $0.69(0.53,0.90)$ & $0.80(0.58,1.12)$ \\
\hline Richest & $0.41(0.31,0.53)$ & $0.58(0.39,0.86) *$ \\
\hline \multicolumn{3}{|l|}{ Place of residence } \\
\hline Urban & 1 & 1 \\
\hline Rural & $1.14(0.94,1.39)$ & $0.78(0.63,0.98) *$ \\
\hline \multicolumn{3}{|c|}{ Presence of handwashing station in dwelling } \\
\hline No & 1 & 1 \\
\hline Yes & $0.48(0.32,0.74)$ & $0.74(0.46,1.21)$ \\
\hline
\end{tabular}

${ }^{*}=$ Significant at $P$-value $<0.05 ; 1=$ Reference category; ${ }^{* *}=$ Variables with $P$-value $>0.2$ but were included in the adjusted model as these variables are clinically relevant or might have some biological plausibility with the outcome

review reported that handwashing promotion may reduce diarrhoea in children [47].

Whilst we did not find an association between household wealth and ARI unlike in other studies [48], our findings was in agreement with the findings of Woldeamanuel and Gebreyesus in Ethiopia [49]. Similarly, we did not observe an association between a child's mother's level of education and ARI contrary to other studies [30, 48].

Our study had strengths and limitations. The national representativeness of MICS data allows for our findings to be generalizable to the entire country. However, our study had several limitations. Our 
Table 3 Factors associated with acute respiratory infection in children under-5 years old $(n=8879)$

\begin{tabular}{|c|c|c|}
\hline Variable & Unadjusted OR (95\% Cl) & Adjusted OR $(95 \% \mathrm{Cl})$ \\
\hline \multicolumn{3}{|l|}{ Child age (months) } \\
\hline $0-5$ & 1 & 1 \\
\hline $6-11$ & $1.44(1.07,1.93)$ & $1.43(1.06,1.93) *$ \\
\hline $12-23$ & $1.44(1.12,1.85)$ & $1.41(1.10,1.82) *$ \\
\hline $24-59$ & $1.14(0.92,1.43)$ & $1.13(0.90,1.41)$ \\
\hline \multicolumn{3}{|l|}{ Gender ** } \\
\hline Boy & 1 & 1 \\
\hline Girl & $0.92(0.8,1.06)$ & $0.93(0.80,1.06)$ \\
\hline \multicolumn{3}{|l|}{ Child's health insurance status } \\
\hline Yes & 1 & 1 \\
\hline No & $0.96(0.85,1.09)$ & $0.94(0.83,1.07)$ \\
\hline \multicolumn{3}{|l|}{ Mothers education } \\
\hline No formal education & 1 & 1 \\
\hline Primary & $1.25(1.01,1.55)$ & $1.22(0.98,1.53)$ \\
\hline Secondary & $1.10(0.96,1.27)$ & $1.06(0.90,1.24)$ \\
\hline College or higher education & $0.89(0.63,1.26)$ & $0.78(0.53,1.15)$ \\
\hline \multicolumn{3}{|l|}{ Source of drinking water ** } \\
\hline Unimproved & 1 & 1 \\
\hline Improved & $0.93(0.79,1.09) * *$ & $0.84(0.70,1.02)$ \\
\hline \multicolumn{3}{|l|}{ Sanitation } \\
\hline Unimproved & 1 & 1 \\
\hline Improved & $0.97(0.85,1.11)$ & $0.92(0.79,1.07)$ \\
\hline \multicolumn{3}{|l|}{ Floor material } \\
\hline Improved & 1 & 1 \\
\hline Unimproved & $0.76(0.59,0.98)$ & $0.77(0.58,1.02)$ \\
\hline \multicolumn{3}{|l|}{ Household Wealth ** } \\
\hline Poorest & 1 & 1 \\
\hline Poor & $1.06(0.86,1.30)$ & $1.02(0.81,1.27)$ \\
\hline Middle & $1.18(0.94,1.48)$ & $1.14(0.88,1.47)$ \\
\hline Rich & $1.07(0.87,1.33)$ & $1.03(0.78,1.34)$ \\
\hline Richest & $1.11(0.89,1.38)$ & $1.08(0.81,1.43)$ \\
\hline \multicolumn{3}{|l|}{ Place of residence } \\
\hline Urban & 1 & 1 \\
\hline Rural & $0.91(0.79,1.04)$ & $0.89(0.75,1.06)$ \\
\hline \multicolumn{3}{|c|}{ Presence of handwashing station in dwelling ** } \\
\hline No & 1 & 1 \\
\hline Yes & $1.08(0.82,1.44)$ & $1.11(0.80,1.56)$ \\
\hline
\end{tabular}

${ }^{*}=$ Significant at $\mathrm{P}$-value $<0.05 ; 1=$ Reference category; ${ }^{* *}=$ Variables with $P$-value $>0.2$ but were included in the adjusted model as these variables are clinically relevant or might have some biological plausibility with the outcome

primary outcomes were self-reported and therefore subject to recall bias. We expect recall bias to be similar between the exposed and unexposed primary variables. Self-reported primary outcomes in our study were not objectively verified (i.e. clinically confirmed) and could potentially overestimate or underestimate the true prevalence of ARI or diarrhoea in our study. Another limitation is that our findings cannot be interpreted causally due to the cross-sectional design of our data. One other limitation is that we could not 
control for seasonal variation of ARI and diarrhoea in our analysis $[18,50]$.

\section{Conclusion}

Children aged 6-11 and 12-23 months had higher prevalence of diarrhoea/ARI compared to children aged 0-5 months. The prevalence of diarrhoea was also lower among children whose mothers had at least a secondary education compared to children whose mothers had no formal education.

\section{Abbreviations}

aPOR: Adjusted prevalence odds ratio; ARI: Acute respiratory infection; CHPS: Community-based health planning and services; JMP: World Health Organization / United Nations Children's Fund Joint monitoring programme for water supply, sanitation and hygiene; MICS: Ghana Multiple Indicator Cluster Survey; UNICEF: United Nations Children's Fund; WHO: World Health Organization

\section{Acknowledgements}

We are grateful to the UNICEF MICS team for making the data available to us.

\section{Authors' contributions}

PAA and MTK conceived the study. PAA analysed the data. PAA and MTK wrote the manuscript and critically reviewed the manuscript for its intellectual content. Both authors read and approved the manuscript for submission.

\section{Funding}

Authors were not funded.

\section{Availability of data and materials}

MICS data is publicly available at: https://mics.unicef.org/surveys

\section{Ethics approval and consent to participate}

This study did not require ethics approval and consent to participate as we analysed de-identified secondary data, which is publicly available.

\section{Competing interests}

None declared.

\section{Author details}

${ }^{1}$ University of Nevada, Reno, School of Community of Health Sciences, Reno, USA. ${ }^{2}$ Ghana Health Service, Nabdam District Health Directorate, Nangodi, Ghana.

Received: 5 January 2021 Accepted: 8 February 2021

Published online: 13 February 2021

\section{References}

1. WHO. Global Health Observatory (GHO) data: Causes of Child Mortality 2017. https://www.who.int/gho/child_health/mortality/causes/en/. Accessed 27 December 2020.

2. UNICEF. One is Too Many: Ending Child Deaths from Pneumonia and Diarrhoea New York: UNICEF; 2016. https://data.unicef.org/wp-content/ uploads/2016/11/UNICEF-Pneumonia-Diarrhoea-report2016-web-version.pdf. Accessed 27 December 2020.

3. WHO. Children: reducing mortality 2019. https://www.who.int/news-room/fa ct-sheets/detail/children-reducing-mortality. Accessed 27 December 2020.

4. UN. Sustainable Development Goals: About the Sustainable Development Goals 2016. https://www.un.org/sustainabledevelopment/sustainabledevelopment-goals/. Accessed 27 December 2020.

5. UNICEF. Committing to Child Survival: A Promise Renewed Progress Report 2015 2015. https://www.unicef.org/publications/files/APR_2015_9_Sep_15. pdf. Accessed 27 December 2020
6. Ghana Health Service. The Health Sector in Ghana: Facts and Figures 2018 https://ghanahealthservice.org/downloads/Facts+Figures_2018.pdf. Accessed 27 December 2020.

7. Ghana Statistical Service. Ghana Multiple Indicator Cluster Survey with an Enhanced Malaria Module and Biomarker, 2011, Final Report. Accra Ghana; 2011

8. Ghana Statistical Service. Multiple Indicator cluster survey (MICS2017/18), survey findings report. Accra, Ghana: GSS; 2018.

9. Kipp AM, Blevins M, Haley CA, Mwinga K, Habimana P, Shepherd BE, et al. Factors associated with declining under-five mortality rates from 2000 to 2013: an ecological analysis of 46 African countries. BMJ Open. 2016;6(1): e007675.

10. Babayara MNK, Addo B. Risk Factors for Child Mortality in the KassenaNankana District of Northern Ghana: A Cross-Sectional Study Using Population-Based Data. Scientifica (Cairo). 2018;2018:7692379.

11. Amugsi DA, Aborigo RA, Oduro AR, Asoala V, Awine T, Amenga-Etego L. Socio-demographic and environmental determinants of infectious disease morbidity in children under 5 years in Ghana. Glob Health Action. 2015;8: 29349.

12. Ankrah Odame E, Akweongo P, Yankah B, Asenso-Boadi F, Agyepong I. Sustainability of recurrent expenditure on public social welfare programmes: expenditure analysis of the free maternal care programme of the Ghana National Health Insurance Scheme. Health Policy Plan. 2014;29(3):271-9.

13. Ministry of Health. Ghana National Newborn Health Strategy and Action Plan 2014-2018. https://www.healthynewbornnetwork.org/hnn-content/ uploads/FINAL_Ghana-Newborn_Strategy_2014July10.pdf. Accessed 28 December 2020.

14. Ministry of Health. Under Five's Child Health Policy: 2007-2015. https://extra net.who.int/nutrition/gina/sites/default/files/GHA\%202007\%20Under\%2 OFive\%27s\%20Child\%20Health\%20Policy\%202007\%20-\%202015.pdf. Accessed 28 December 2020

15. Nyonator FK, Awoonor-Williams JK, Phillips JF, Jones TC, Miller RA. The Ghana community-based health planning and services initiative for scaling up service delivery innovation. Health Policy Plan. 2005;20(1):25-34.

16. Kumi-Kyereme A, Amo-Adjei J. Household wealth, residential status and the incidence of diarrhoea among children under-five years in Ghana. J Epidemiol Glob Health. 2016:6(3):131-40.

17. Tetteh J, Takramah WK, Ayanore MA, Adoliba Ayanore A, Bisung E, Alamu J. Trends for diarrhea morbidity in the Jasikan District of Ghana: estimates from district level diarrhea surveillance data, 2012-2016. J Trop Med. 2018; 2018:4863607.

18. Anyorikeya M, Ameme DK, Nyarko KM, Sackey SO, Afari E. Trends of diarrhoeal diseases in children under five years in the war memorial hospital-Navrongo, Ghana: 2010-2013. Pan Afr Med J. 2016;25(Suppl 1):8.

19. Escribano-Ferrer B, Gyapong M, Bruce J, Narh Bana SA, Narh CT, Allotey NK, et al. Effectiveness of two community-based strategies on disease knowledge and health behaviour regarding malaria, diarrhoea and pneumonia in Ghana. BMC Public Health. 2017;17(1):948.

20. UNICEF. Multiple Indicator Cluster Survey (MICS) 2019. https://mics.unicef. org/. Accessed 28 December 2020

21. Khan S, Hancioglu A. Multiple Indicator cluster surveys: delivering robust data on children and women across the globe. Stud Fam Plan. 2019;50(3): 279-86.

22. National Bureau of Statistics and UNICEF. Multiple indicator cluster survey 2016-2017, survey findings report. Abuja, Nigeria; 2017.

23. Furuse $Y$, Tamaki $R$, Okamoto $M$, Saito-Obata $M$, Suzuki $A$, Saito $M$, et al. Association between preceding viral respiratory infection and subsequent respiratory illnesses among children: a prospective cohort study in the Philippines. J Infect Dis. 2019;219(2):197-205.

24. WHO, UNICEF. Safely managed drinking water - thematic report on drinking water 2017. https://data.unicef.org/wp-content/uploads/2017/ 03/safely-managed-drinking-water-JMP-2017-1.pdf. Accessed 28 December 2020.

25. UNICEF, WHO. Progress on Drinking Water,Sanitation and Hygiene: 2017 Update and SDG baselines Geneva, Switzerland 2017. https://www.unicef. org/publications/files/Progress_on_Drinking_Water_Sanitation_and_ Hygiene_2017.pdf. Accessed 28 December 2020.

26. Adebowale SA, Morakinyo OM, Ana GR. Housing materials as predictors of under-five mortality in Nigeria: evidence from 2013 demographic and health survey. BMC Pediatr. 2017;17(1):30. 
27. UNICEF. MICS Methodological Papers: No 3 and No 4 2016. https://mics. unicef.org/news_entries/65/MICS-METHODOLOGICAL-PAPERS:-NO-3-ANDNO-4-. Accessed 28 December 2020.

28. Dagne $H$, Andualem $Z$, Dagnew B, Taddese AA. Acute respiratory infection and its associated factors among children under-five years attending pediatrics ward at University of Gondar Comprehensive Specialized Hospital, Northwest Ethiopia: institution-based cross-sectional study. BMC Pediatr. 2020;20(1):93.

29. Schreiber-Gregory D, Jackson H. Multicollinearity: what is it, why should we care, and how can it be controlled? 2017. https://support. sas.com/resources/papers/proceedings17/1404-2017.pdf. Accessed 28 December 2020.

30. Tazinya AA, Halle-Ekane GE, Mbuagbaw LT, Abanda M, Atashili J, Obama MT. Risk factors for acute respiratory infections in children under five years attending the Bamenda regional Hospital in Cameroon. BMC Pulm Med. 2018;18(1):7.

31. Savitha AK, Gopalakrishnan S. Determinants of acute respiratory infections among under five children in a rural area of Tamil Nadu. India J Family Med Prim Care. 2018;7(6):1268-73.

32. Solomon O, Odu O, Amu E, Solomon O, Bamidele J, Emmanuel E, et al. Prevalence and risk factors of acute respiratory infection among under fives in rural communities of Ekiti State, Nigeria. Global Journal of Medicine and Public Health. 2018;7(1).

33. Tampah-Naah A. Maternal and Child Level Factors Associated with Childhood (0-23 months) Diarrhoea in Ghana: A Pooled Analysis of National Representative Datasets. Ghana J Dev Studies. 2019;16(2).

34. Woldu W, Bitew BD, Gizaw Z. Socioeconomic factors associated with diarrheal diseases among under-five children of the nomadic population in Northeast Ethiopia. Trop Med Health. 2016;44:40.

35. Anteneh ZA, Hassen HY. Determinants of acute respiratory infection among children in Ethiopia: a multilevel analysis from Ethiopian demographic and health survey. Int J Gen Med. 2020;13:17-26.

36. Mulatya DM, Mutuku FW. Assessing comorbidity of diarrhea and acute respiratory infections in children under 5 years: evidence from Kenya's demographic health survey 2014. J Prim Care Community Health. 2020;11: 2150132720925190

37. Arifeen S, Black RE, Antelman G, Baqui A, Caulfield L, Becker S. Exclusive breastfeeding reduces acute respiratory infection and diarrhea deaths among infants in Dhaka slums. Pediatrics. 2001;108(4):E67.

38. Woldemicael G. Diarrhoeal morbidity among young children in Eritrea: environmental and socioeconomic determinants. J Health Popul Nutr. 2001; 19(2):83-90.

39. Azage M, Kumie A, Worku A, Bagtzoglou AC. Childhood diarrhea in high and low hotspot districts of Amhara region, Northwest Ethiopia: a multilevel modeling. J Health Popul Nutr. 2016;35:13.

40. Edwin P, Azage M. Geographical variations and factors associated with childhood diarrhea in Tanzania: a National Population Based Survey 201516. Ethiop J Health Sci. 2019;29(4):513-24.

41. Alebel A, Tesema C, Temesgen B, Gebrie A, Petrucka P, Kibret GD. Prevalence and determinants of diarrhea among under-five children in Ethiopia: a systematic review and meta-analysis. PLoS One. 2018;13(6): e0199684.

42. Freudenberg N, Galea S, Vlahov D. Beyond urban penalty and urban sprawl: back to living conditions as the focus of urban health. J Community Health. 2005;30(1):1-11.

43. Kamm KB, Feikin DR, Bigogo GM, Aol G, Audi A, Cohen AL, et al. Associations between presence of handwashing stations and soap in the home and diarrhoea and respiratory illness, in children less than five years old in rural western Kenya. Tropical Med Int Health. 2014; 19(4):398-406.

44. Ram PK, DiVita MA, Khatun-e-Jannat K, Islam M, Krytus K, Cercone E, et al. Impact of intensive Handwashing promotion on secondary household influenza-like illness in rural Bangladesh: findings from a randomized controlled trial. PLoS One. 2015;10(6):e0125200.

45. Luby SP, Halder AK, Huda TM, Unicomb L, Johnston RB. Using child health outcomes to identify effective measures of handwashing. Am J Trop Med Hyg. 2011;85(5):882-92.

46. Null C, Stewart CP, Pickering AJ, Dentz HN, Arnold BF, Arnold CD, et al. Effects of water quality, sanitation, handwashing, and nutritional interventions on diarrhoea and child growth in rural Kenya: a clusterrandomised controlled trial. Lancet Glob Health. 2018;6(3):e316-e29.
47. Ejemot-Nwadiaro RI, Ehiri JE, Arikpo D, Meremikwu MM, Critchley JA. Hand washing promotion for preventing diarrhoea. Cochrane Database Syst Rev. 2015;9:CD004265.

48. Yaya S, Bishwajit G. Burden of Acute Respiratory Infections Among UnderFive Children in Relation to Household Wealth and Socioeconomic Status in Bangladesh. Trop Med Infect Dis. 2019;4(1).

49. Woldeamanuel B, Gebreyesus H. Prevalence and risk factors for chestrelated symptoms of acute respiratory tract infections among under five children: case of Ethiopia. Trends in Biomedical Research. 2019;2.

50. Annan A, Ebach F, Corman VM, Krumkamp R, Adu-Sarkodie Y, Eis-Hübinger AM, et al. Similar virus spectra and seasonality in paediatric patients with acute respiratory disease. Ghana and Germany Clin Microbiol Infect. 2016; 22(4):340-6.

\section{Publisher's Note}

Springer Nature remains neutral with regard to jurisdictional claims in published maps and institutional affiliations.
Ready to submit your research? Choose BMC and benefit from:

- fast, convenient online submission

- thorough peer review by experienced researchers in your field

- rapid publication on acceptance

- support for research data, including large and complex data types

- gold Open Access which fosters wider collaboration and increased citations

- maximum visibility for your research: over $100 \mathrm{M}$ website views per year

At BMC, research is always in progress.

Learn more biomedcentral.com/submissions 